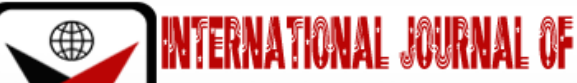

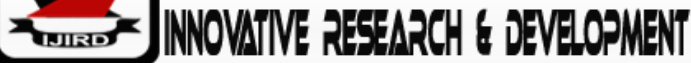

ISSN 2278-0211 (Online)

\section{Investigation and Prediction of the Influence of Shielding Gas Composition on Residual Stress}

\begin{tabular}{|c|}
\hline Nihad Saliu Achekuogene \\
Principal Engineer, Department of Mechanical/ Transport, \\
Auchi Polytechnic, Auchi, Nigeria \\
J. O. Osarenmwinda \\
Professor, Department of Production Engineering, \\
University of Benin, Nigeria \\
Dr. R. S. Ebhojiaye \\
Senior lecturer, Department of Production Engineering, \\
University of Benin, Nigeria \\
Dr. C. I. Eboigbe \\
Lecturer, Department of Production Engineering, \\
University of Benin, Nigeria
\end{tabular}

\begin{abstract}
:
Residual stresses are internal stress distribution locked up within a material or weldment area. They usually exist inside the material (or weld) irrespective of external loading. These stresses are generated upon equilibrium of materials after plastic deformation caused either by applied mechanical loads, thermal loads or phase change and they play key role in the failure of these joints. Therefore, accurate prediction and reduction of residual stress are critical in improving the quality of a weldment. Welding process generates residual stresses of various magnitudes, and the combination of shielding gases at various percentages might affect the amount of residual stresses in weldment. The resultant residual stress from shielding gas on welded joint is unknown and has been based on trial and error assumption. This study therefore, focused on the investigation and prediction of shielding gas mixtures to minimize residual stress formation in mild steel welded joint, employing scientific design of experiment using BoxBeckhen's design (BBD) matrix, statistical and mathematical models to measure the residual stresses from various gas mixtures. The argon ( $\mathrm{Ar})$ and carbon-dioxide $\left(\mathrm{CO}_{2}\right)$ shielding gas variations considered for the experiment were: $100 \% w t$. Ar and $0 \% w t . \mathrm{CO}_{2} ; 75 \% w t$. Ar and 25\%wt. $\mathrm{CO}_{2} ; 50 \% w t$. Ar and $50 \% w t . \mathrm{CO}_{2} ; 25 \% w t$. Ar and $75 \% w t . \mathrm{CO}_{2}$, $0 \%$ wt $\mathrm{Ar}$ and $100 \% w t . \mathrm{CO}_{2}$. The weldment produced by shielding gas of $100 \% w t$. Ar and $0 \% w t . \mathrm{Co}_{2}$ had the highest residual stress while the weldment of 50\%wt. Ar and 50\%wt. $\mathrm{CO}_{2}, 25 \%$ wt. Ar and $75 \% w t . \mathrm{CO}_{2}, 0 \% w t$. Ar and $100 \% w t$. $\mathrm{CO}_{2}$ produced weld with lesser residual stress values.
\end{abstract}

Keywords: Shielding gas, residual stress, artificial neural network, argon, carbon dioxide

\section{Introduction}

A study carried out by Maritime Traffic Safety System Development Plan showed that in the year 2007-2011, the percentage of the factors causing sea accidents especially by technical factors was $59 \%$. The data indicated that the weld joint is the most critical part of the structure, and therefore welding researchers and practitioners should pay greater attention to welded joints (Yustiasih et al., 2016).

Metal inert gas welding (MIG), by definition, is an arc welding process which produces the coalescence of metals by heating them with an arc between a continuously fed filler metal electrode and the work. The process uses shielding from an externally supplied gas to protect the molten weld pool. The application of MIG generally requires DC+ (reverse) polarity to the electrode. Air in the weld zone is displaced by a shielding gas in order to prevent contamination of the molten weld puddle. This contamination is caused mainly by nitrogen, oxygen and water vapor present in the atmosphere.

To avoid these problems associated with contamination of the weld puddle, shielding gases are used. The three most common shielding gases used in MIG welding are Argon, Helium, Carbon Dioxide. These gases can be used alone, in combinations or mixed with oxygen, and each provides unique benefits and drawbacks in any given application. Argon and carbon dioxide $\left(\mathrm{Ar}-\mathrm{CO}_{2}\right)$ combination was as the shielding gas in this study. $\mathrm{Ar}-\mathrm{CO}_{2}$ blend are versatile mixtures for welding carbon, all kinds of structural steel, farm implements and machinery, low alloy and some stainless steel. Although, weld metallic properties are primarily controlled by the composition of the consumables, but shielding gas can influence the weld strength, ductility, toughness and corrosion resistance of finished weldment. According to Noland (2015), two of 
the most commonly used gases for metal inert gas welding (MIG) of carbon steel are carbon dioxide $\left(\mathrm{CO}_{2}\right)$ and argon (Ar). Together these gases can complement strength while also equalizing weaknesses. $90 \% \mathrm{Ar}-10 \% \mathrm{CO}_{2}, 85 \% \mathrm{Ar}-15 \% \mathrm{CO}_{2}$, $75 \% \mathrm{Ar}-25 \% \mathrm{CO}_{2}$ were used as the shielding gas blend for carbon steel MIG weld. Nguyen (2015) reported thattungsten inert gas (TIG) welding uses only inert gas which is argon, helium, or a mixture of the two. While it is technically possible to weld with mixtures that contain gases like carbon dioxide or oxygen, it is not at all recommended. Carbon dioxide will lead to flare-ups, overheating, and make quite a mess. For stainless steel, a tri-mix of helium, argon, and carbon dioxide or helium, argon and oxygen are sometimes used. One example would be a tri-mix of 90 percent helium, 7.5 percent argon, and 2.5 percent $\mathrm{CO}_{2}$. Again, the added levels of helium increase heat while oxygen helps to penetrate thicker metals and stabilize the arc. Both $\mathrm{CO}_{2}$ and helium require higher voltages to sustain a stable arc, and helium is the most expensive of the inert gases.

Ebrahimnia et al. (2009) reported that pure argon is not suitable for welding steel since it cannot provide the desired arc stability and weld bead characteristic. Argon with $\mathrm{CO}_{2}$ and/or $\mathrm{O}_{2}$ is therefore preferred. Mixtures of argon with $5-20 \%$ carbon dioxide are very common for the welding of mild and low alloyed steels. The study further claimed that increasing the amount of $\mathrm{CO}_{2}$ in the shielding gas reduces the amount of inclusion and porosity in the weld. Inclusions in the weldment initiate direct cracks and promote brittle fracture. Increasing the $\mathrm{CO}_{2}$ percentage also enhances the formation of acicular ferrite, which improves weld toughness and decreases hardness. According to Biro et al. (2002), the formation of an oxide layer on the surface base metal drastically decreases the amount of laser beam absorption. Therefore, shielding gas can influence laser beam absorption by weld metal surface through affecting plasma and the molten pool surface. Chung et al. (1999) studied the effect of shielding gas types on $\mathrm{CO}_{2}$ tailored blank weldability of low carbon automotive galvanized steel and stated that the metallurgical and mechanical properties of weld metal are relatively influenced by the reaction between molten pool and the shielding gas. It was also found that the weld penetration and the joint strength are strongly dependent on the type of shielding gas used, and the maximum travel speed and gas flow rate necessary to form a keyhole weld are dependent on the shielding gas type. Gadallah et al. (2012) reported that during welding, the shielding gas also interacts with the welding wire to determine the strength, toughness and corrosion resistance of weld deposits. The shielding gas also affects the residual contents of hydrogen, nitrogen and oxygen dissolved in the weld metal. Gadallah et al. (2011), in their study on the Influence of Shielding Gas Composition on the Properties of Flux-Core Arc Welds of Plain Carbon Steel, used six different shielding gas compositions (95\%wt. Ar and 5 \%wt. $\mathrm{CO}_{2}, 90 \%$ wt. Ar and $10 \%$ wt. $\mathrm{CO}_{2}, 82 \%$ wt. Ar and $18 \%$ wt. $\mathrm{CO}_{2}, 80 \%$ wt. Ar and $20 \%$ wt. $\mathrm{CO}_{2}, 75 \%$ wt. Ar and 25 $\%$ wt. $\mathrm{CO}_{2}, 50 \%$ wt. Ar and $50 \%$ wt. $\mathrm{CO}_{2}$ ) in addition to pure Ar and $\mathrm{CO}_{2}$. They pointed out that the shielding gas compositions have a significant effect on the arc stability and efficiency, deposition rate, microstructure, chemical and mechanical properties of mild carbon steel welds.

Kou (2003) stated that welding residual stress is an unavoidable result in the workpiece, which plays a key role in the failure of the weld Part. Macherauch and Kloos (1987) reported that micro stresses are homogenous or inhomogeneous on a micro scale. All manufacturing and fabricating processes introduce residual stresses into the manufactured part. Extreme service loading may also change the state of residual stress in the part. The effect of residual stress may be either beneficial or detrimental depending upon the sign, magnitude and distribution of the stress. Many methods are widely in use for measuring residual stress in welded components and they include X-ray diffraction, the hole-drilling method and other destructive and non-destructive methods. Mechanical techniques are destructive since they use strain gauge which requires that the component be drilled or cut. Among the non-destructive techniques, some are based on acoustic or magnetic effects; whereas the diffraction methods utilize X-ray or neutron beams to evaluate the residual stress. Fitapztrick et al. (2002) introduced the use of X-ray diffraction to measure residual stress. Due to its short wavelength, X-rays penetrate a very thin surface layer of material, up to tens of microns, and are then reflected back from the atomic planes they have penetrated. By knowing the wavelength, the change in 2-theta, and the change in the interplanar spacing, the stress can be calculated from the strain using Hooke's law. According to Etin-Osa et al. (2020), residual stresses remain in an engineering material, especially metallic materials, after the original applied load has been removed and its measurement will help reveal areas in fabricated materials highly stressed. They presented a design of a portable residual stress measuring device based on the magnetic Barkhausen noise principle. This was achieved by using two permanent magnets, a pickup coil, amplifier and an analogue to digital converter to create the hardware.

Many efforts have been made to optimize Ar- $\mathrm{CO}_{2}$ mixture for weld spatter, but little is known about residual stresses created from the combinations of these gases. This study therefore focuses on investigation and prediction of shielding gas composition in MIG welding process with the aim of removing residual stresses formed in mild steel welded joints.

\section{Methodology}

Mild steels coupons (or plates) with dimension of $60 \mathrm{~mm} \times 50 \mathrm{~mm} \times 10 \mathrm{~mm}$ were prepared for this study, using the metal inert gas (MIG) welding process. The welding input parameters in this study were welding voltage, welding current and wire feed rate as shown in Table 1.Five (5) experimental mix ratios of $\mathrm{Ar}^{-} \mathrm{CO}_{2}$ shielding gases were considered. They include $100 \%$ wt. Ar and $0 \%$ wt. $\mathrm{CO}_{2}, 75 \%$ wt. Ar and $25 \%$ wt. $\mathrm{CO}_{2}, 50 \%$ wt $\mathrm{Ar}$ and $50 \%$ wt. $\mathrm{CO}_{2}, 25 \%$ wt. Ar and $75 \%$ wt. $\mathrm{CO}_{2}$, and $0 \% w t$. Ar and $100 \% w t . \mathrm{CO}_{2}$. (Where wt. is weight).The design of experiment (DOE) was done using Box-Beckhen's design (BBD) matrix. The DOE gave 17 experimental runs and a total of 85 experimental data were generated for the five (5) shielding gas variations. Table 2 shows the BBD matrix. The residual stresses were examined using the X-ray diffraction technique. The results obtained from the residual stress test, were used to train the ANN tool for validation and prediction of responses. 


\begin{tabular}{|c|c|c|c|c|}
\hline Factors & Unit & Symbol & Low (-1) & High (+1) \\
\hline Welding Current & Ampere & I & 110 & 200 \\
\hline Welding Voltage & Volts & V & 20 & 24 \\
\hline Wire Feed Rate & $\mathrm{mm} / \mathrm{s}$ & WFR & 45 & 65 \\
\hline
\end{tabular}

Table 1: Process Parameters and Their Levels

\begin{tabular}{|c|c|c|c|}
\hline & Factor 1 & Factor 2 & Factor 3 \\
\hline Run & A:Welding Current & B:Welding Voltage & 55 \\
\hline 1 & 110 & 20 & 45 \\
\hline 2 & 110 & 22 & 55 \\
\hline 3 & 155 & 22 & 55 \\
\hline 4 & 200 & 22 & 55 \\
\hline 5 & 155 & 22 & 65 \\
\hline 6 & 200 & 20 & 55 \\
\hline 7 & 155 & 24 & 55 \\
\hline 8 & 155 & 22 & 55 \\
\hline 9 & 155 & 22 & 65 \\
\hline 10 & 110 & 24 & 65 \\
\hline 11 & 200 & 22 & 55 \\
\hline 12 & 110 & 22 & 55 \\
\hline 13 & 155 & 22 & 45 \\
\hline 14 & 200 & 24 & 45 \\
\hline 15 & 155 & 24 & 65 \\
\hline 16 & 155 & 20 & \\
\hline 17 & 155 & 20 & \\
\hline
\end{tabular}

Table 2: Box-Beckhen's Design Matrix (BBD)

\section{Results and Discussion}

The results obtained for the 5 different mix ratios of shielding gases (i.e. Ar- $\mathrm{CO}_{2}$ ratio) with respect to the residual stresses, the modelling, prediction and validation of the results using ANN are shown below.

\subsection{Results of Residual Stress Obtained from $B B D$}

Table 3 shows the residual stress responses obtained for the 5 different mix ratios of the shielding gases of argon and carbon dioxide. Eighty five (85) experimental data was generated using the Box-Bekhen's design of experiment for the residual stress.

\begin{tabular}{|c|c|c|c|c|c|c|c|c|}
\hline & Factor 1 & Factor 2 & Factor 3 & $\begin{array}{c}\text { Response } \\
1 \\
\end{array}$ & $\begin{array}{c}\text { Response } \\
2 \\
\end{array}$ & $\begin{array}{c}\text { Response } \\
3 \\
\end{array}$ & $\begin{array}{c}\text { Response } \\
4 \\
\end{array}$ & $\begin{array}{c}\text { Response } \\
5 \\
\end{array}$ \\
\hline Run & $\begin{array}{c}\text { A:Welding } \\
\text { Current }\end{array}$ & $\begin{array}{c}\text { B:Welding } \\
\text { Voltage }\end{array}$ & $\begin{array}{c}\text { C:Wire } \\
\text { Feed Rate }\end{array}$ & $\begin{array}{c}100 \% \mathrm{Ar}- \\
0 \% \mathrm{CO} 2\end{array}$ & $\begin{array}{l}75 \% \mathrm{Ar}- \\
25 \% \mathrm{CO} 2\end{array}$ & $\begin{array}{l}50 \% \mathrm{Ar}- \\
50 \% \mathrm{CO} 2\end{array}$ & $\begin{array}{l}25 \% \mathrm{Ar}- \\
75 \% \mathrm{CO} 2\end{array}$ & $\begin{array}{c}0 \% \mathrm{Ar}- \\
100 \% \mathrm{CO} 2\end{array}$ \\
\hline & Ampere & Volts & $\mathrm{mm} / \mathrm{s}$ & $\mathrm{MPa}$ & $\mathrm{MPa}$ & $\mathrm{MPa}$ & $\mathrm{MPa}$ & $\mathrm{MPa}$ \\
\hline 1 & 110 & 20 & 55 & 304 & 192 & 178 & 271 & 189 \\
\hline 2 & 110 & 22 & 45 & 259 & 156 & 163 & 179 & 167 \\
\hline 3 & 155 & 22 & 55 & 321 & 198 & 219 & 229 & 278 \\
\hline 4 & 200 & 22 & 45 & 280 & 190 & 235 & 188 & 208 \\
\hline 5 & 155 & 22 & 55 & 312 & 206 & 211 & 246 & 239 \\
\hline 6 & 200 & 20 & 55 & 263 & 183 & 174 & 166 & 195 \\
\hline 7 & 155 & 24 & 65 & 292 & 181 & 179 & 186 & 186 \\
\hline 8 & 155 & 22 & 55 & 301 & 200 & 201 & 216 & 254 \\
\hline 9 & 155 & 22 & 55 & 318 & 211 & 223 & 230 & 242 \\
\hline 10 & 110 & 24 & 55 & 255 & 158 & 177 & 163 & 172 \\
\hline 11 & 200 & 22 & 65 & 274 & 188 & 181 & 181 & 187 \\
\hline 12 & 110 & 22 & 65 & 299 & 229 & 266 & 197 & 234 \\
\hline 13 & 155 & 22 & 55 & 317 & 227 & 223 & 252 & 260 \\
\hline 14 & 200 & 24 & 55 & 272 & 159 & 172 & 226 & 153 \\
\hline 15 & 155 & 24 & 45 & 275 & 172 & 168 & 192 & 180 \\
\hline 16 & 155 & 20 & 45 & 291 & 179 & 161 & 206 & 192 \\
\hline 17 & 155 & 20 & 65 & 311 & 220 & 184 & 236 & 218 \\
\hline
\end{tabular}

Table 3: Residual Stress Responses for the Five Shielding Gases Using the BBD Method

To train a neural network for predicting the responses, the feed forward back propagation algorithm was selected, with input layer of the network using the hyperbolictangent (tan-sigmoid) transfer function to calculate the layer output 
from the network input, then the output layer uses the linear (purelin) transfer function. The hidden neurons were set at 10 neurons per layer and the network performance was calculated using the mean square error of regression (MSEREG).

The ANN architecture in Figure1 consist of three input (3) layers, ten (10) hidden layer and one output layer.

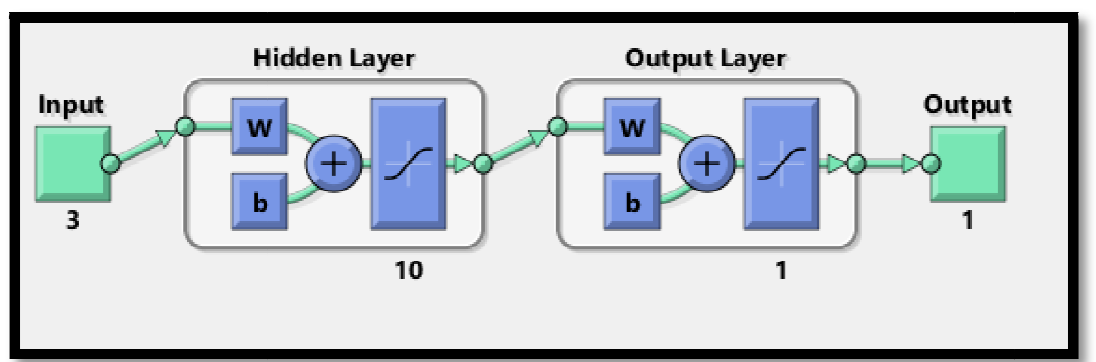

Figure 1: ANN Architecture with Three Input Layers

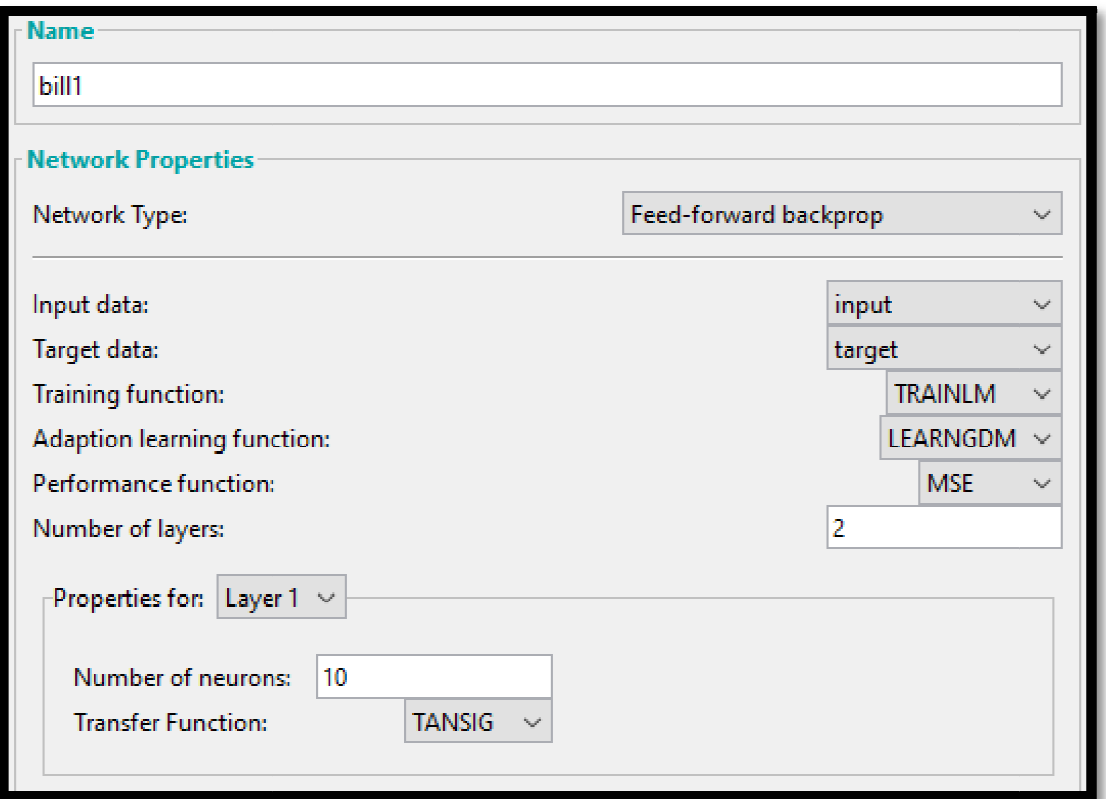

Figure 2: Network Properties Interphase for Predicting Weld Response of the Shielding Gas

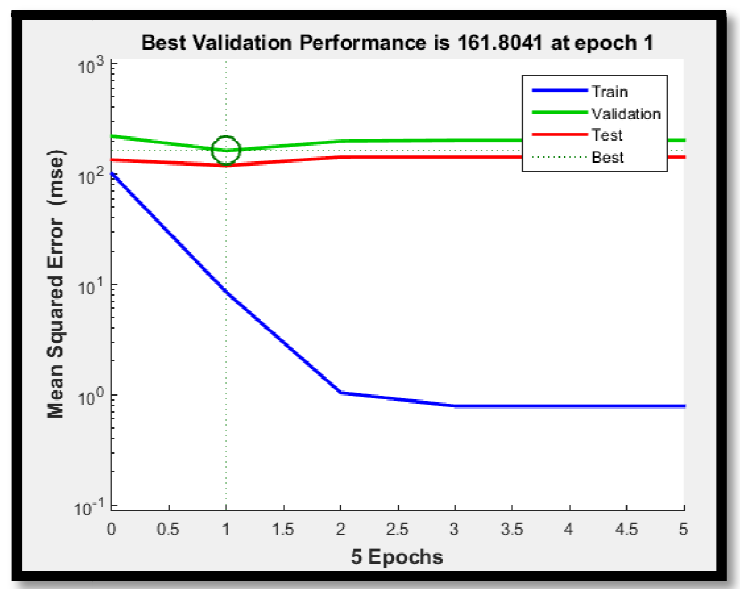

Figure 3: Performance Curve of 100\%Wt. ArAnd 0\%Wt. $\mathrm{CO}_{2}$ Shielding Gas 


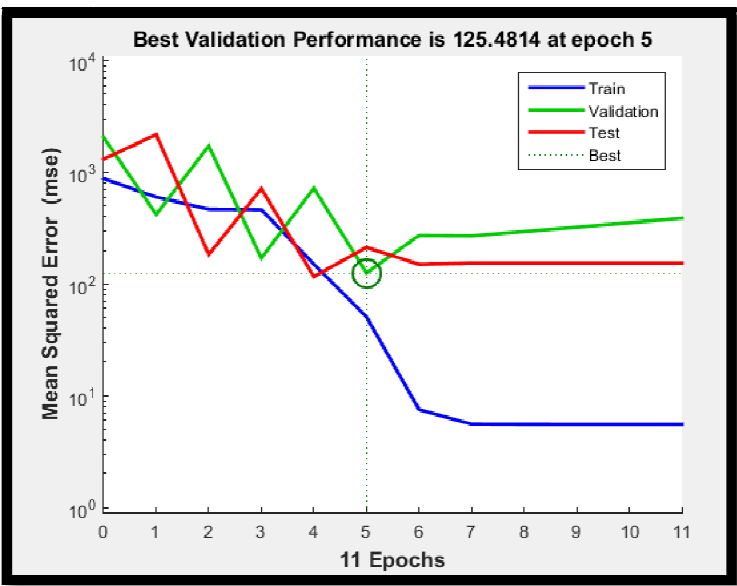

Figure 4: Performance Curve of 75\%Wt. Ar and 25\%Wt. $\mathrm{CO}_{2}$ Shielding Gas

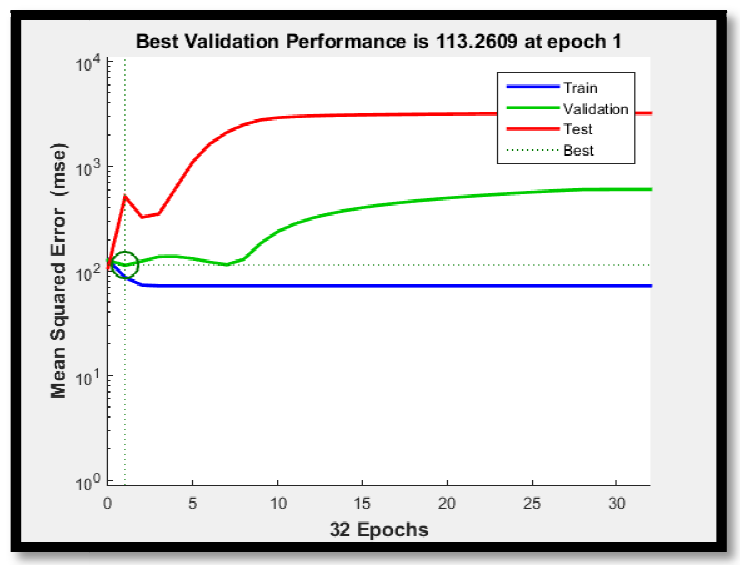

Figure 5: Performance Curve Of 25\%Wt. Arand 75\% Wt. $\mathrm{CO}_{2}$ shielding Gas

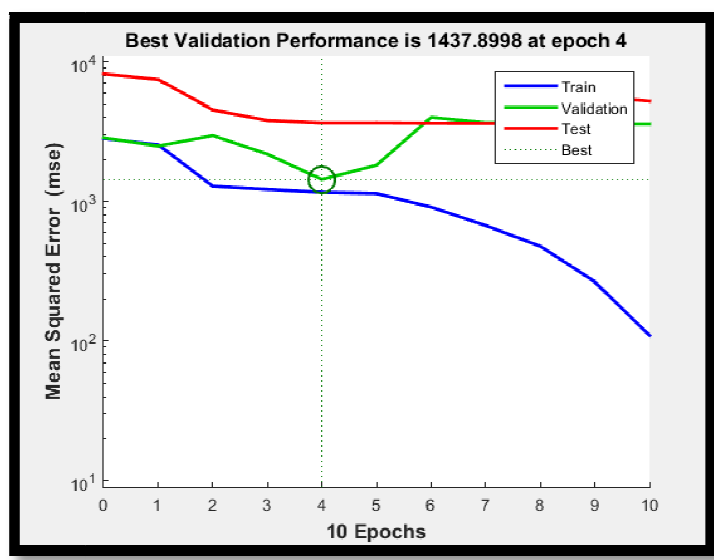

Figure 6: Performance Curve of 0\%Wt. Arand 100\%Wt. $\mathrm{CO}_{2}$ shielding Gas 


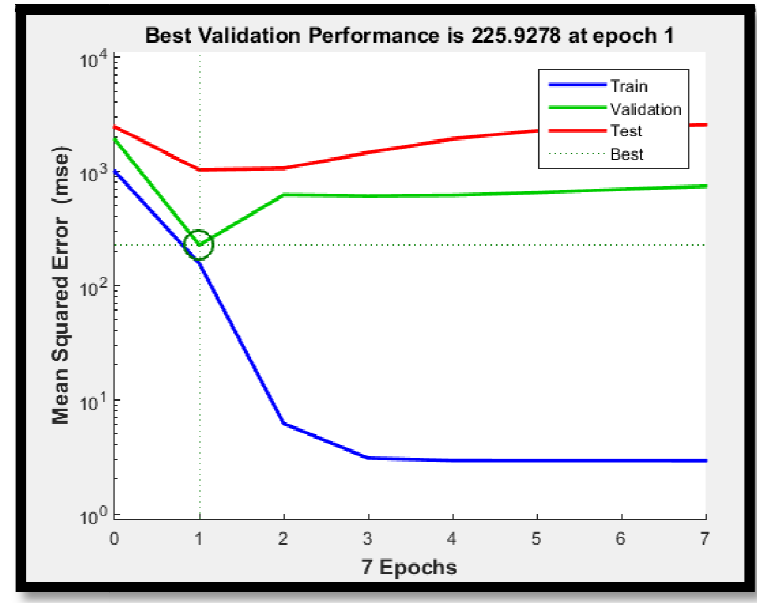

Figure 7: Performance Curve of $50 \% W$ t.Ar and $50 \% W$ t. $\mathrm{CO}_{2}$ shielding Gas

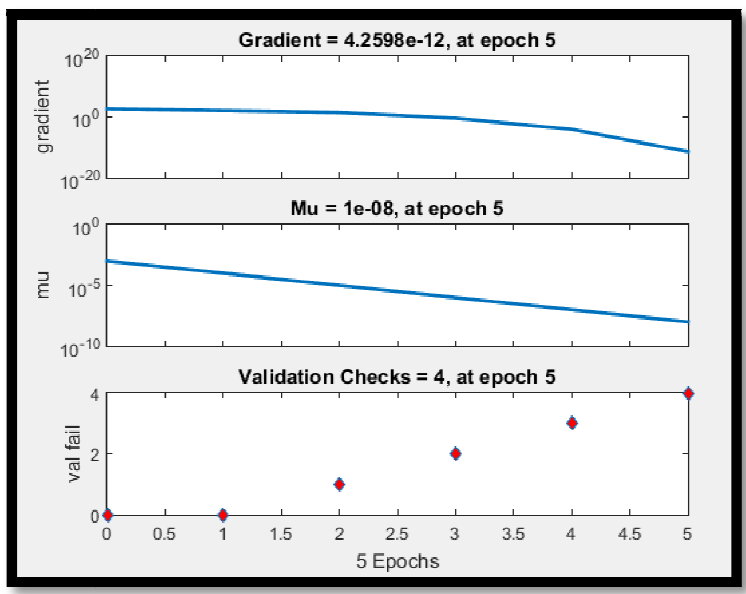

Figure 8: Neural Network Gradient Plot for 100\%Wt.Ar and 0\%Wt.CO ${ }_{2}$ shielding Gas

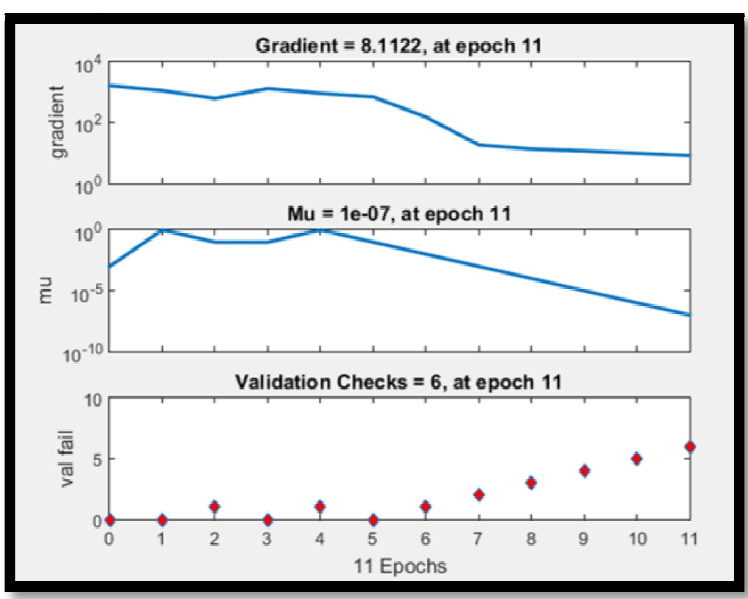

Figure 9: Neural Network Gradient Plot for 75\%Wtar and $25 \% \mathrm{WtCO}_{2}$ shielding Gas 


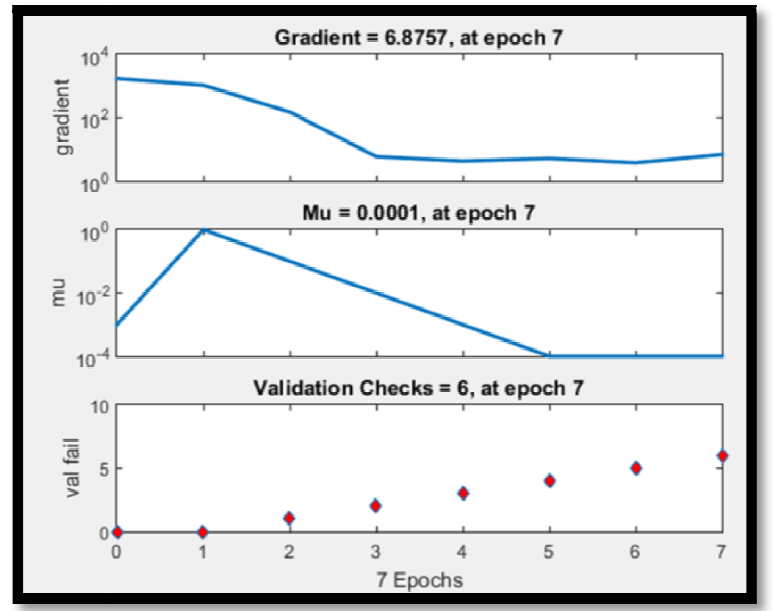

Figure 10: Neural Network Gradient Plot for $50 \%$ Wt.Ar and $50 \%$ Wt. $\mathrm{CO}_{2}$ Shielding Gas

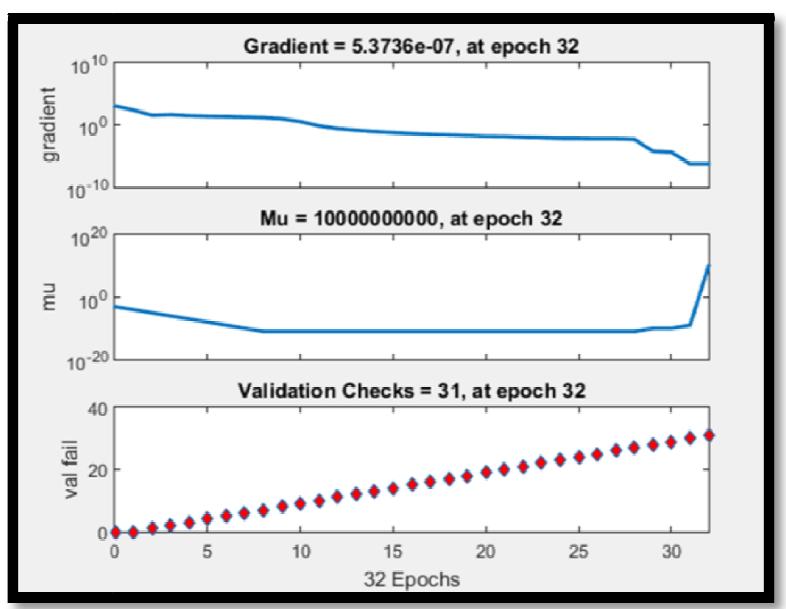

Figure 11: Neural Network Gradient Plot for $25 \%$ Wt.Ar and $75 \%$ Wt. $\mathrm{CO}_{2}$ Shielding Gas

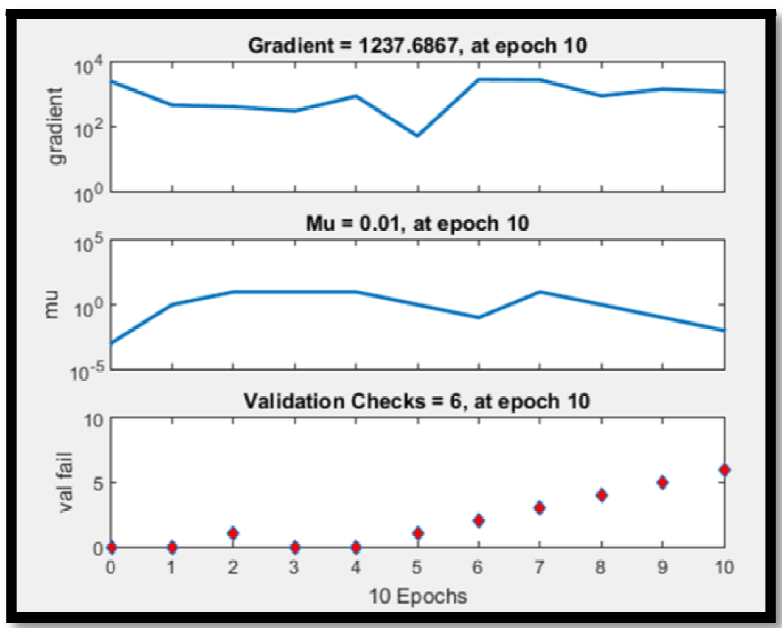

Figure 12: Neural Network Gradient Plot for $0 \%$ Wt. Arand $100 \%$ Wt. $\mathrm{CO}_{2}$ Shielding Gas

To test the reliability of the trained network, the network was employed to predict its own values of residual stresses for $100 \%$ wt.Ar and $0 \%$ wt.CO $2 ; 75 \%$ wt.Ar and $25 \%$ wt. $\mathrm{CO}_{2} ; 50 \%$ wt.Ar and $50 \%$ wt. $\mathrm{CO}_{2} ; 25 \%$ wt.Ar and $75 \%$ wt. $\mathrm{CO}_{2}$; $0 \%$ wt.Ar and $100 \%$ wt. $\mathrm{CO}_{2}$ shielding gas ratio, with the same input parameters generated from the BBD. Based on the observed and the predicted values of residual stress obtained from the shielding gas mix ratios, a regression plot of outputs were thereafter generated as shown in Figures 13,14,15, 16 and 17 respectively. 

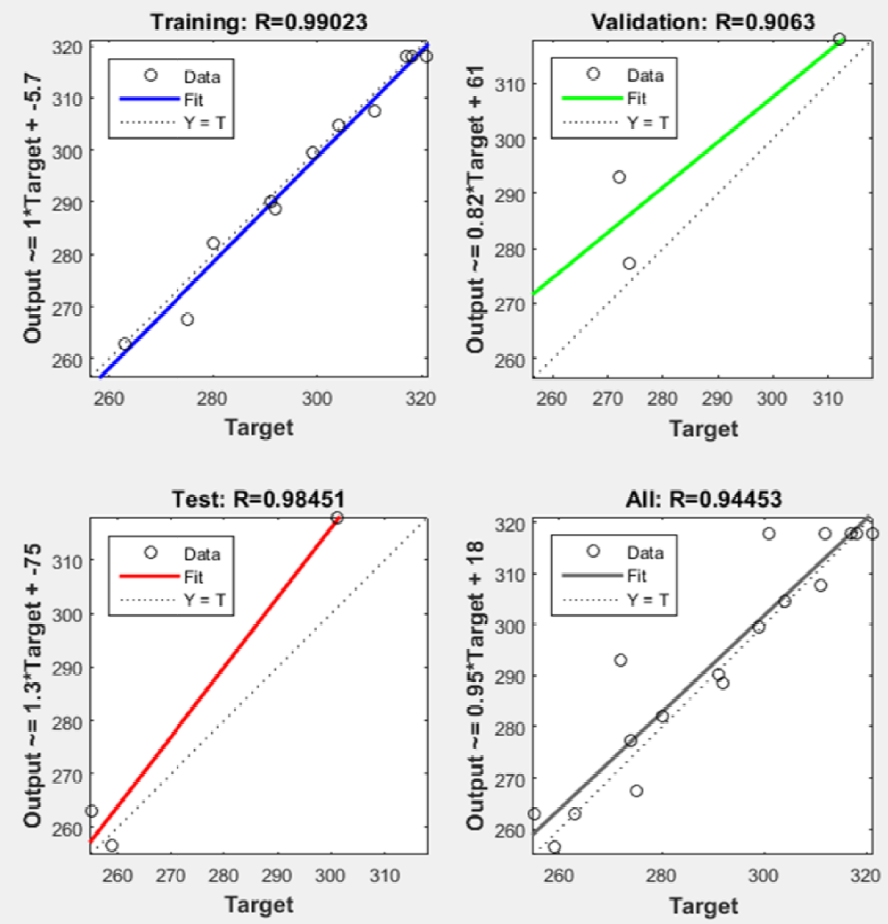

Figure 13: Regression Plot of Training, Validation and Testing for Residual Stress Using 100\% Arand 0\% $\mathrm{CO}_{2}$ Shielding Gas

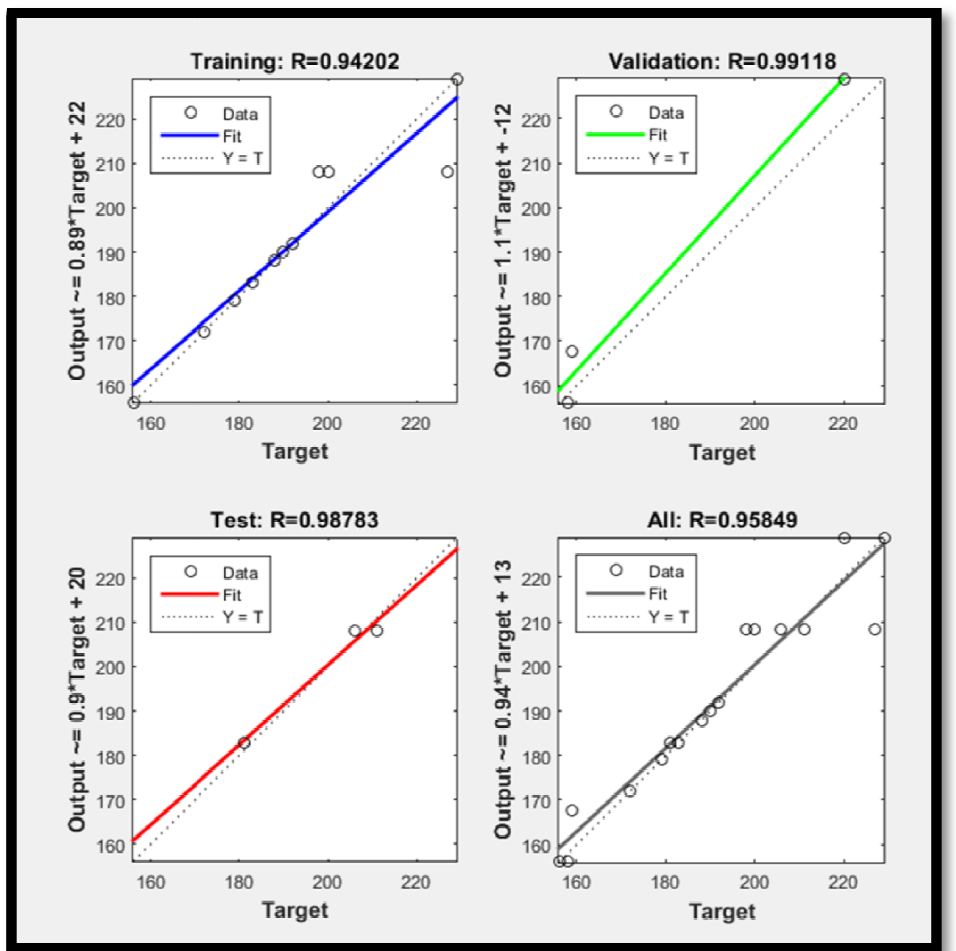

Figure 14: Regression Plot of Training, Validation and Testing for Residual Stress Using $75 \% \mathrm{Ar}$ and $25 \% \mathrm{CO}_{2}$ Shielding Gas 

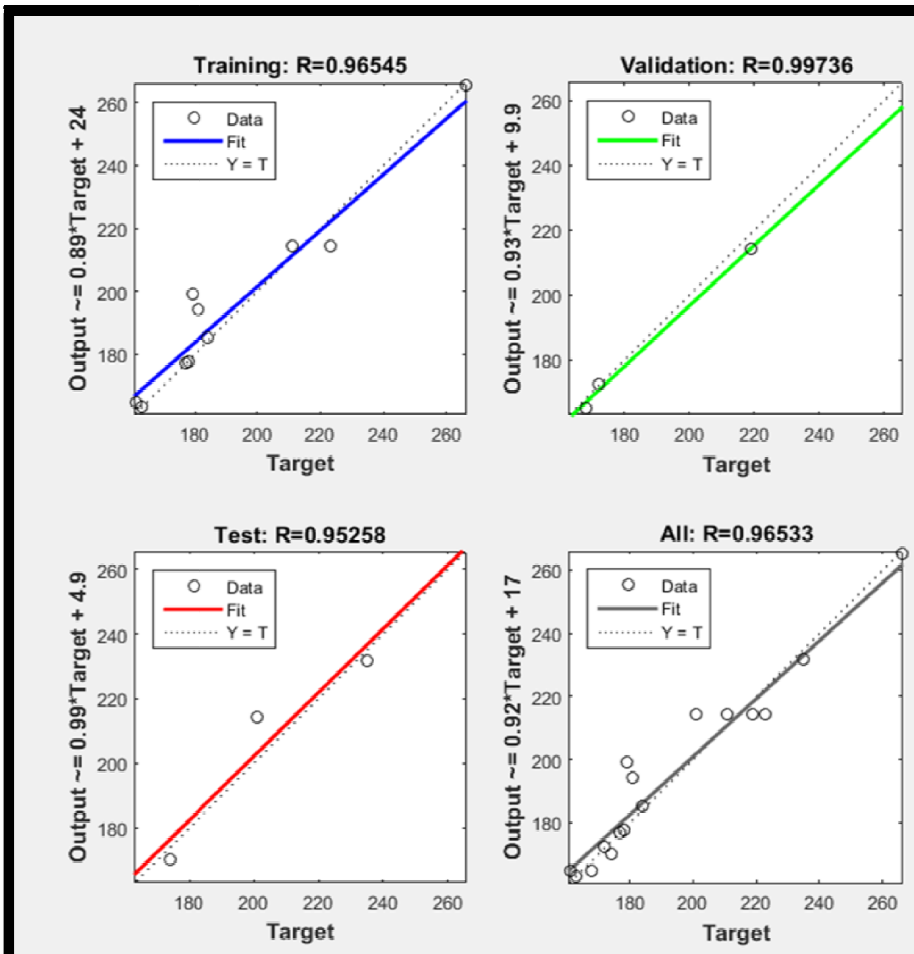

Figure 15: Regression Plot of Training, Validation and Testing for Residual Stress Using 50\% Ar and 50\% $\mathrm{CO}_{2}$ Shielding Gas

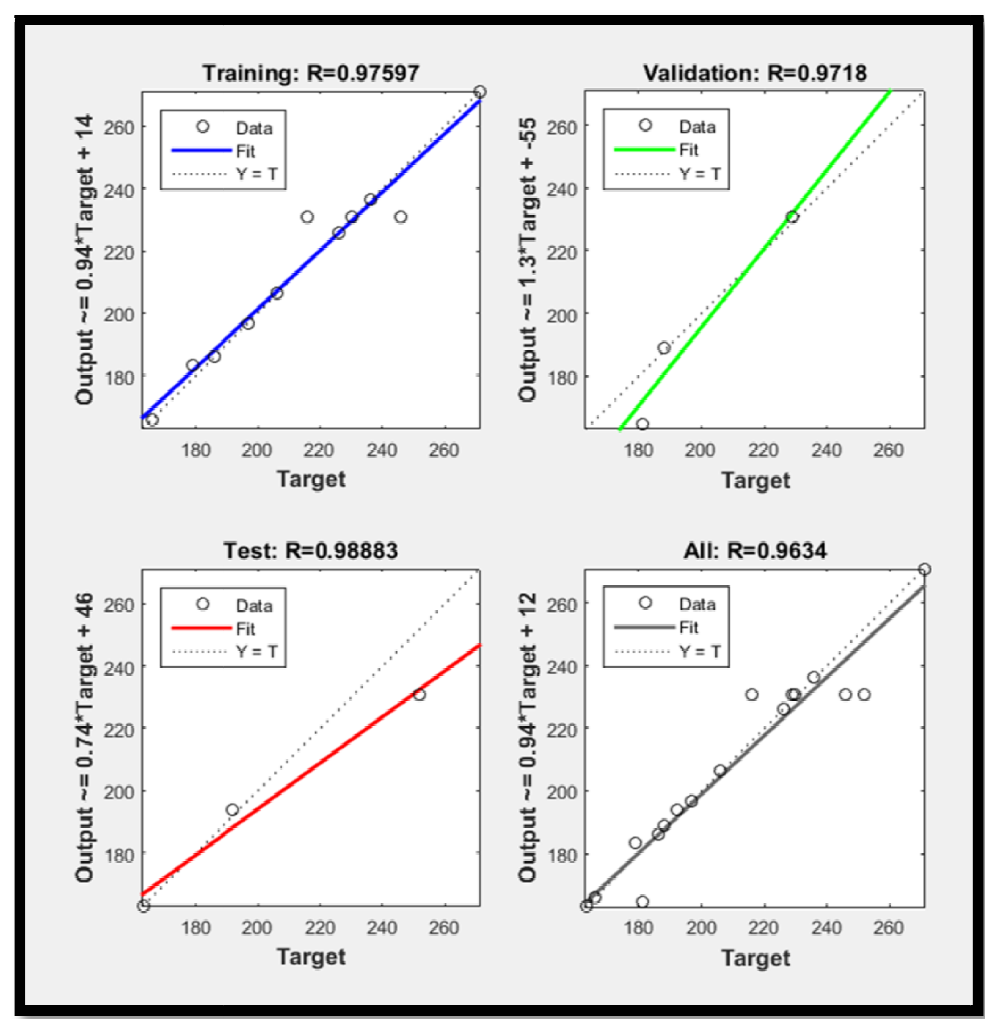

Figure 16: Regression Plot of Training, Validation and Testing for Residual Stress Using 25\% Ar and $75 \% \mathrm{CO}_{2}$ Shielding Gas 


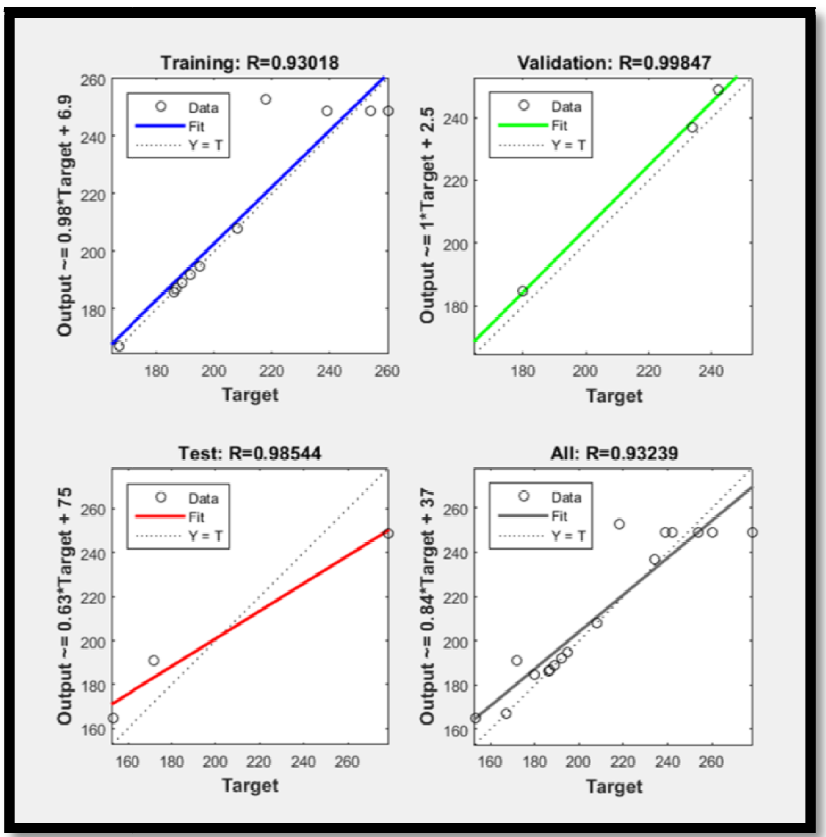

Figure 17: Regression Plot of Training, Validation and Testing for Residual Stress Using $0 \% \mathrm{Ar}$ and $100 \% \mathrm{CO}_{2}$ Shielding Gas

From the computed values of the correlation coefficient (R) as shown in Figures 13, 14, 15, 16 and 17, it was established that the network has been accurately trained and can be employed to predict the residual stresses beyond the scope of experimentation, with respect to the shielding gas mix ratios considered in this study.

Table 4 shows the comparison of experimental and ANN results for the various $\mathrm{Ar}$ and $\mathrm{CO}_{2}$ shielding gas mixtures. Figure 18 shows the time series plot for the shielding gas with minimal residual stress.

\begin{tabular}{|c|c|c|c|c|c|c|c|c|c|}
\hline & 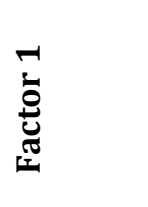 & 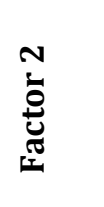 & 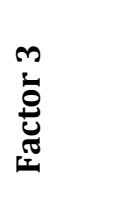 & & 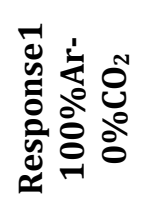 & 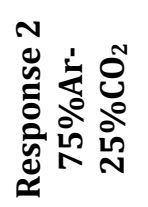 & 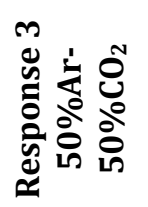 & 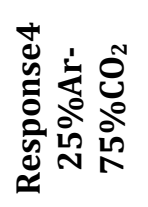 & 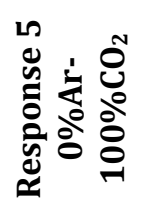 \\
\hline$\Xi$ & 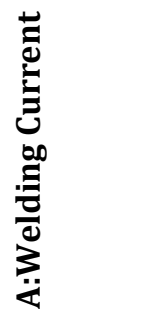 & 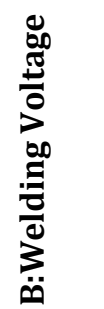 & 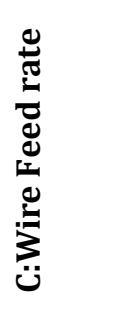 & 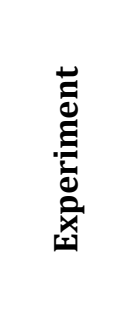 & 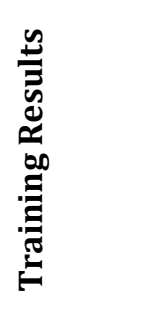 & 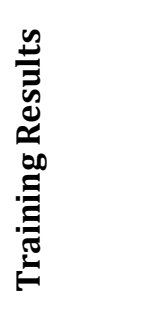 & 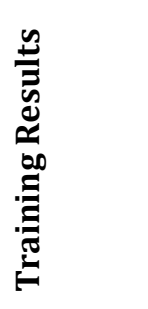 & 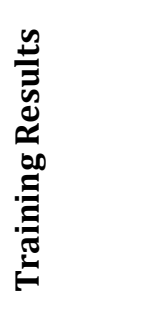 & $\begin{array}{c}\text { Training } \\
\text { Result }\end{array}$ \\
\hline & Ampere & Volts & $\mathrm{mm} / \mathrm{s}$ & MPa & MPa & MPa & MPa & MPa & MPa \\
\hline 1 & 110 & 20 & 55 & 304.00 & 304.69 & 191.90 & 177.71 & 271.00 & 189.00 \\
\hline 2 & 110 & 22 & 45 & 259.00 & 256.49 & 156.00 & 163.21 & 183.46 & 167.00 \\
\hline 3 & 155 & 22 & 55 & 321.00 & 317.90 & 208.25 & 214.27 & 230.74 & 248.75 \\
\hline 4 & 200 & 22 & 45 & 280.00 & 282.11 & 189.89 & 231.80 & 189.03 & 208.00 \\
\hline 5 & 155 & 22 & 55 & 312.00 & 317.90 & 208.25 & 214.27 & 230.74 & 248.75 \\
\hline 6 & 200 & 20 & 55 & 263.00 & 262.93 & 183.02 & 170.36 & 166.00 & 195.00 \\
\hline 7 & 155 & 24 & 65 & 292.00 & 288.68 & 182.88 & 199.36 & 185.99 & 186.00 \\
\hline 8 & 155 & 22 & 55 & 301.00 & 317.90 & 208.25 & 214.27 & 230.74 & 248.75 \\
\hline 9 & 155 & 22 & 55 & 318.00 & 317.90 & 208.25 & 214.27 & 230.74 & 248.75 \\
\hline 10 & 110 & 24 & 55 & 255.00 & 263.07 & 156.03 & 177.04 & 163.01 & 191.13 \\
\hline 11 & 200 & 22 & 65 & 274.00 & 277.32 & 187.99 & 194.10 & 164.64 & 187.00 \\
\hline 12 & 110 & 22 & 65 & 299.00 & 299.52 & 229.00 & 265.39 & 196.84 & 236.92 \\
\hline 13 & 155 & 22 & 55 & 317.00 & 317.90 & 208.25 & 214.27 & 230.74 & 248.75 \\
\hline 14 & 200 & 24 & 55 & 272.00 & 292.96 & 167.52 & 172.54 & 226.00 & 164.72 \\
\hline 15 & 155 & 24 & 45 & 275.00 & 267.63 & 171.98 & 164.96 & 194.01 & 184.63 \\
\hline 16 & 155 & 20 & 45 & 291.00 & 290.19 & 179.02 & 164.66 & 206.23 & 192.00 \\
\hline 17 & 155 & 20 & 65 & 311.00 & 307.61 & 229.00 & 185.16 & 236.20 & 252.79 \\
\hline
\end{tabular}

Table 4: Experimental and ANN Results for Residual Stresses 


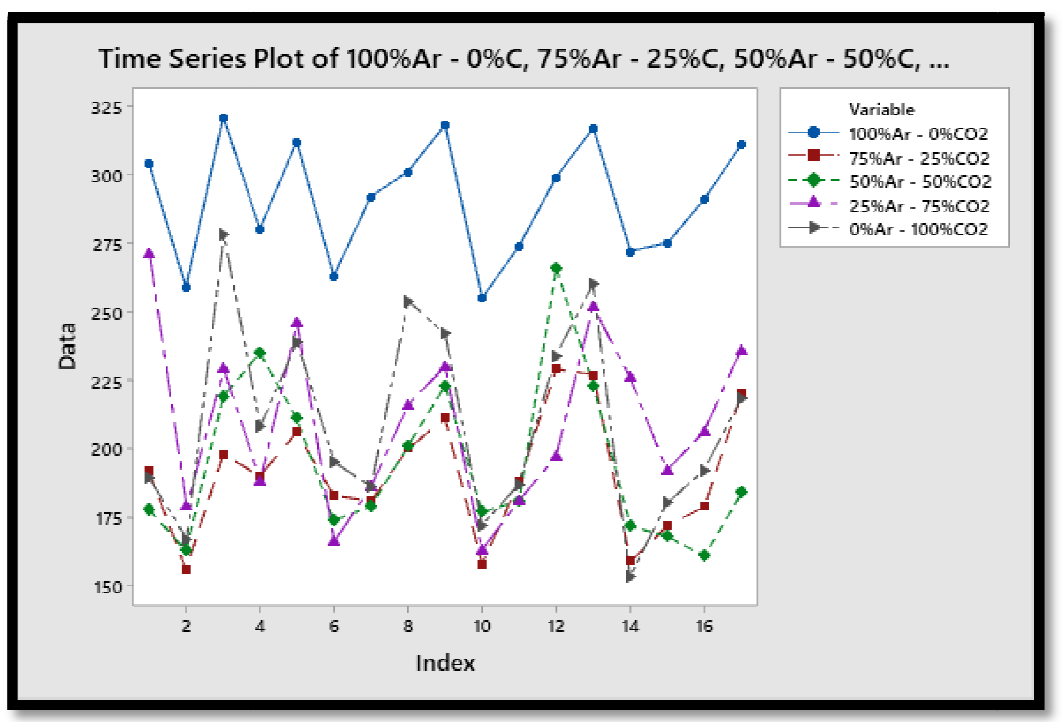

Figure 18: Time Series Plot of Shielding Gas with Minimal Residual Stress

Figure 18 showed that the network is robust enough to predict the residual stress of $0 \% \mathrm{Ar}$ and $100 \% \mathrm{CO}_{2} ; 25 \% \mathrm{Ar}$ and $75 \% \mathrm{CO}_{2} ; 50 \% \mathrm{Ar}$ and $50 \% \mathrm{CO}_{2} ; 75 \% \mathrm{Ar}$ and $25 \% \mathrm{CO}_{2}$; and $100 \% \mathrm{Ar}$ and $0 \% \mathrm{CO}_{2}$ shielding gas mix ratios, with coefficient of determination $\left(\mathrm{R}^{2}\right)$ values of $86.9 \%, 92.8 \%, 93.2 \%, 91.9 \%, 89.2 \%$ respectively. The high $\mathrm{R}^{2}$ values showed that there is a minimal error in the network.

\section{Conclusion}

This study has successfully investigated and predicted residual stresses in mild steel MIG welded joint of different mix ratios of argon and carbon dioxide shielding gas. X-ray diffraction technique was used to measure the residual stress on weldment. The ANN predictive tool was employed in this study. The BBD matrix was used to train the network to predict unknown response beyond the experimental values. The results from this study showed that shielding gas has strong influence on the residual stress in MIG welding process of mild steel. Shielding gas mix ratio of $100 \% \mathrm{Ar}$ and $0 \% \mathrm{CO}_{2}$ produced the weldment with the highest residual stresses while, shielding gas mx ratios of $50 \% \mathrm{Ar}$ and $50 \% \mathrm{CO}_{2}, 25 \% \mathrm{Ar}$ and $75 \% \mathrm{CO}_{2}$, and $0 \% \mathrm{Ar}$ and $100 \% \mathrm{CO}_{2}$ produced welds with less residual stress values. The shielding gas mix ratio that produced the least residual stress was $75 \% \mathrm{Ar}$ and $25 \% \mathrm{CO}_{2}$.

\section{References}

i. Biro, E., Weckman, D.C., Zhou, Y. (2002), 'Pulsed Nd: YAG Laser Welding of Copper Using Oxygenated Assist Gases'. Metall Mater Trans A, pp.2019-2030

ii. Chung, B, Rhee, S, Lee, C. (1999), the effect of shielding gas types on $\mathrm{CO}_{2}$ laser tailored blank weldability of low carbon automotive galvanized steel. Materials Science and Engineering journal: Volume 272, Issue 2, Pages $357-$ 362

iii. Crawley, M. J. (2007) The R Book. John Wiley \& Sons, Ltd., Chichester, viii + 942 pp, ISBN 978-0-470-51024-7, hardcover

iv. Mohamad Ebrahimnia, MassoudGoodarzi, MeisamNouri, Mohsen Sheikh (2009Study of the effect of shielding gas composition on the mechanical weldproperties of steel ST 37-2 in gas metal arc welding

v. ErdalKaradeniz, UgurOzsarac, Ceyhan Yildiz (2007). The effect of process parameters on penetration in gas metal arc welding processes. Materials \& Design, Volume 28, Issue 2, Pages 649-656

vi. Etin-Osa C.E., Achebo J. I. and Obahiagbon K. O. (2020), Design and fabrication of portable weld residual stress measuring device using MBN principle. NIPES Journal of Science and Technology Research 2(3) pp. 70-84 pISSN-2682-5821, eISSN-2682-5821

vii. Fitapztrick, M. E., Fry, A. T., Holdway, P., Kandil, F.A., Shackleton, J.and L. Suominen, (2002) Determination of residual stresses by X-ray diffraction, National Physical Laboratory, Guide No. 52.

viii. Kou, S. (2003) Welding Metallurgy. 2nd Edition, Wiley Interscience, New Jersey. Page 121-148

ix. Macherauch, E. and K. H. Kloos, (1987) Origin, Measurement and Evaluation of Residual Stress, Residual Stress in Science and Technology, Vol. 1, pp. 3-27.

x. Nguyen, O. (2015). What is GTAW (Gas Tungsten Arc Welding)? Retrieved from https://www.weldingschool.com/blog/welding/what-is-gtaw-gas-tungsten-arc-welding/

xi. Pal, S., Pal, S.K. and Samantaray, A.K. (2008) Artificial neural network modeling of weld joint strength prediction of a pulsed metal inert gas welding process using arc signals, Journal of materials processing technology, (202), 464-474.

xii. Rajkumar, G.B. and Murugan, N. (2012) Prediction of Weld Bead Geometry using Artificial Neural Networks on 2205 Duplex Stainless Steel. European Journal of Scientific Research, ISSN 1450-216X (78), 85-92. 
xiii. RamyGadallah, RaoufFahmy, Tarek Khalifa, AlberSadek (2012), Influence of Shielding Gas Composition on the Properties of Flux-Cored Arc Welds of Plain Carbon Steel. International Journal of Engineering and Technology Innovation 2(1):1-12

xiv. Samantha Noland. (2015), Shielding gas blends for carbon steel GMAW. 363 Walnut St., Memphis, TN 38126

xv. YustiasihPurwaningrum, Triyono M. WirawanPU.,andFandi A. (2016) Effect of shielding gas mixture on gas metal arc welding (GMAW) of low carbon steel (LR Grade A). Key Engineering Materials. ISSN: 1662-9795, Vol. 705, pp 250-254 